\title{
Descobertas de exoplanetas pelo método do trânsito
}

Transit method and discovery of exoplanet

\author{
W. C. Santos*1,2, R.G.G. Amorim ${ }^{1,2}$ \\ ${ }^{1}$ Faculdade UnB Gama, Universidade de Brasília, Brasília, DF, Brasil \\ ${ }^{2}$ Instituto de Física, Universidade de Brasília, Brasília, DF, Brasil
}

Recebido em 27 de Setembro, 2016. Revisado em 16 de Novembro, 2016. Aceito em 21 de Setembro, 2016.

\begin{abstract}
Apresentamos neste trabalho uma breve revisão sobre o método de trânsito na detecção de exoplanetas. O trânsito é uma técnica baseada na redução do brilho de uma estrela quando o exoplaneta passa na sua frente percorrendo o seu disco, com respeito à linha de visada. O método de trânsito é responsável por $23 \%$ das deteç̧ões de exoplanetas. Nesse sentido, discutimos de forma pedagógica os detalhes da técnica, deduzindo as principais equações. Por fim, a aplicação do método na detecção do exoplaneta COROT-1b foi analisado.
\end{abstract}

Palavras-chave: método do transito; exoplanetas

This issue reports a brief review about transit method of detecting extrasolar planet (exoplanet). When a exoplanet crosses (transits) in front of its host star's disk along the line of sight, then the observed visual brightness of the star drops by a small amount. The transit method is responsible for $23 \%$ of some important new discoveries of exoplanets. In this sense, we explain didactically the conceptual and calculational details of transit method. As a result of application of the transit method, we applied it to exoplanet COROT-1b.

Keywords: transit method; exoplanets

\section{Introdução}

A detecção de exoplanetas constitui um dos temas da Astrofísica que tem recebido muito destaque nos últimos anos. As principais agências internacionais que realizam pesquisas astronômicas, ESO, NASA e ESA, fomentam projetos que possuem como principal meta a detecção de planetas extra-solares. Uma das técnicas de deteç̧ão de exoplanetas que tem crescido é o método de trânsito [1,2]. Trânsito, eclipse e ocultação são essencialmente o mesmo fenômeno, pois ocorrem quando um objeto astronômico passa na frente de outro com respeito à linha de visada. O parâmetro que os diferencia é a distância angular do astro até o observador. Durante um eclipse, os dois objetos são de tamanhos angulares comparáveis, como por exemplo a Lua eclipsando o Sol. $\mathrm{Na}$ ocultação, a distância angular de um dos objetos é pequena comparado ao outro, como a Lua

*Endereço de correspondência: wytler.cordeiro@gmail.com ocultando uma estrela. O trânsito é o oposto da ocultação, o objeto que possui tamanho angular menor fica a frente do outro objeto, como exemplo, temos a projeção de um dos satélites de Júpiter no disco do planeta [3,4].

O trânsito possui uma longa história de interesse para os astrônomos. Parte dessa história pode ser narrada sob o ponto de vista do trânsito de Vênus e Mercúrio em relação ao Sol. Nesse arcabouço, nos séculos XVIII e XIX, os astrônomos ficaram interessados em medir a posição de Vênus em relação ao Sol para determinar a distância da Terra ao Sol [4]. Explicitando mais o processo, quando Mercúrio e Vênus transitam o Sol, observações do trânsito a partir de dois pontos bem separados na superfície da Terra, combinados com simples trigonometria, nos fornecem a distância da Terra ao Sol. O trânsito de Vênus é mais nítido e melhor de ser observado do que o de Mercúrio, devido ao fato dele ser mais próximo da Terra. Porém, Vênus transita o Sol apenas 4 vezes em 243 anos, no intervalo de 8, 121,5, 8 e 
105,5 anos. O último trânsito ocorreu em 8 de julho de 2004; sendo assim, o próximo ocorrerá somente no próximo século. Alicerçada em tal fenômeno, a astronomia moderna faz uso de seus instrumentos mais precisos e potentes para examinar o mesmo tipo de observação, não de Vênus e Sol, mas de estrelas distantes e seus exoplanetas [2], conforme representado na figura (1).

O método do trânsito é responsável por cerca de $23 \%$ das detecções dos exoplanetas conhecidos até o momento. Esse número o coloca na segunda posição no ranking de detecções, sendo superado apenas pelo método Doppler [5]. O primeiro exoplaneta estudado pelo método de trânsito foi o HD 209458b, o qual já tinha sido detectado em 1999 com o uso do método Doppler. A primeira detecção de exoplanetas pelo método de trânsito ocorreu em 2002. Em tal ocasião, foram detectados os planetas OGLE-TR-56b e OGLE-TR-10b, os quais possuíam massas iguais a, respectivamente, 0,6 e 1,3 vezes a massa de Júpiter. O período orbital deles é 3,1 e 1,2 dias, respectivamente [1,2, 6].

Atualmente, com instrumentos astronômicos de muita sensibilidade é possível observar o trânsito de planetas extrasolares em frente ao disco de suas estrelas hospedeiras $1,4,6,7]$. A missão Kepler da NASA, lançada em março de 2009, mapeou uma pequena região vizinha ao nosso sistema solar com um alcance de observação de 3.000 anos-luz, confirmando a existência de 2.331 exoplanetas e catalogando 4.696 candidatos a exoplanetas 8,9 . Se pensarmos numa situação hipotética, na qual um observador fora do sistema solar com instrumentos de observações iguais aos da missão Kepler, localizado até uma distância de 3.000 anos-luz do nosso sistema solar, ele observaria que o trânsito de Vênus em frente ao disco solar, diminuiria o brilho do Sol

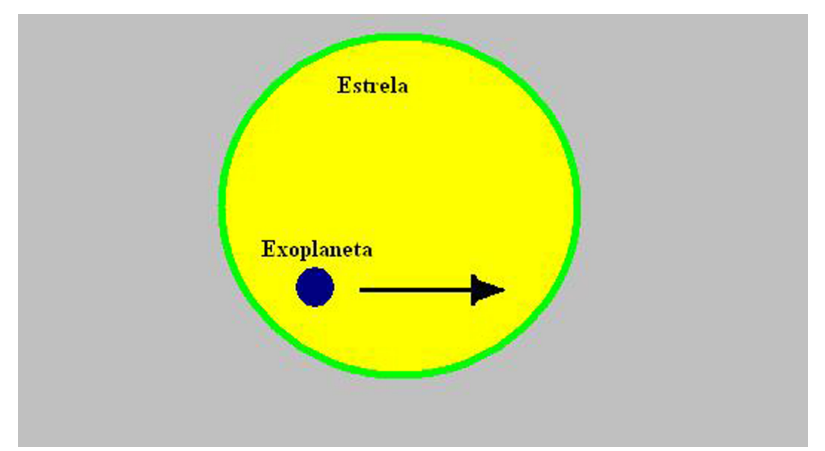

Figura 1: Trânsito de um exoplaneta em frente à sua estrela hospedeira visto aqui da Terra. de $0,008 \%$ a cada 225 dias (aqui da Terra não se vê trânsitos de Vênus nesse intervalo de 225 dias pois a órbita de Vênus é inclinada de $3,4^{\circ}$ em relação à órbita da Terra). De forma análoga, o trânsito de Júpiter, o maior planeta do sistema solar, reduziria o brilho do Sol em apenas 1\% 2].

Para que um exoplaneta seja confirmado como autêntico, é preciso observar pelo menos uns três trânsitos separados pelo mesmo intervalo de tempo, o período de revolução do exoplaneta em torno da estrela hospedeira, pois apenas um única observação de diminuição do brilho de uma estrela pode ter outras causas [2]. A limitação do método de trânsito está no fato de só funcionar para exoplanetas que tem sua órbita com quase $90^{\circ}$ de inclinação em relação ao plano do céu, para que esse exoplaneta passe na frente do disco da estrela hospedeira com respeito à linha de visada e cause diminuição do brilho da estrela.

Neste trabalho, apresentamos uma revisão pedagógica sobre o método de trânsito e aplicamos tal técnica no estudo do exoplaneta COROT-1b. Esperamos que este artigo constitua uma bom material de consulta a professores e estudantes que desejarem conhecer um pouco melhor alguns conceitos de radiação de corpo negro, leis de Kepler e astrofísica. Nesse sentido, a apresentação será baseada nos seguintes pontos: na seção 2 , revisamos as leis de Kepler e a lei da radiação térmica para estrelas; na seção 3 estudamos o método de trânsito, deduzindo as principais equações; na seção 4 elencamos uma aplicação da técnica, fazendo o estudo do exoplaneta COROT-1b; na seção 5 apresentamos as nossas considerações finais e perspectivas.

\section{Leis de Kepler e as leis da radiação térmica para as estrelas}

\subsection{Leis de Kepler}

Da mesma forma que as leis de Kepler (que são obtidas a partir das leis da Mecânica e da lei da Gravitação Universal) nos dão o entendimento dos movimentos dos planetas em nosso sistema solar [10,11, essas mesmas leis regem a astrodinâmica dos sistemas extra-solares. As três leis de Kepler para o movimento planetário podem ser descritas como: 
- Primeira lei: A trajetória dos planetas em torno do sol é elíptica, com o sol situado em um foco;

- Segunda lei: O raio vetor que une o Sol a qualquer planeta varre áreas iguais em tempos iguais;

- Terceira lei: O quadrado do período de revolução de um planeta é proporcional ao cubo do semi-eixo maior da sua órbita.

A primeira lei de Kepler é um consequência da força gravitacional ser inversamente proporcional ao quadrado da distância, tal que as trajetórias fechadas possíveis são círculos ou elipses.

A segunda lei é uma conseqüência da conservação do momento angular. A taxa de variação instantânea da área varrida pelo vetor posição em relação ao tempo é constante, o que implica que o vetor posição varre áreas iguais em tempos iguais.

A terceira lei de Kepler é deduzida a partir das leis de Newton para a dinâmica e da lei da Gravitação Universal,

$$
\tau^{2}=\left(\frac{4 \pi^{2}}{G M}\right) a^{3},
$$

onde $\tau$ é o período de revolução do planeta em torno da estrela, $a$ é o semi-eixo maior da órbita elíptica, $G$ é a constante da Gravitação Universal e $M$ é a massa da estrela no foco da elipse. Podemos expressar o coeficiente $\left(\frac{4 \pi^{2}}{G M}\right)$ em termos de uma constante para o sistema solar. Como a massa do Sol é muito maior que a massa de qualquer planeta temos que $M \approx M_{\odot}$. Se tomarmos para a Terra $\tau=1$ ano e $a=1 \mathrm{UA}=1,5 \times 10^{11} \mathrm{~m}$, teremos que:

$$
\frac{\tau^{2}}{a^{3}}=\frac{4 \pi^{2}}{G M_{\odot}}=1 \frac{\mathrm{ano}^{2}}{\mathrm{UA}^{3}}
$$

Após a determinação do valor da constante gravitacional, $G=6,67 \times 10^{-11} \mathrm{~m}^{3} / \mathrm{Kg} \mathrm{s}^{2}$ foi possível determinar a massa do Sol $M_{\odot}$ que é aproximadamente $2 \times 10^{30} \mathrm{~kg}$. Mais detalhes podem ser encontrados nas referências $5,10,11$.

\subsection{Leis da radiação térmica aplicadas às estrelas}

As estrelas podem ser modeladas como esferas de gases ionizados - plasma - de grande massa. As estrelas são aquecidas na escala de milhares de graus Kelvin na superfície, que emitem radiação eletromagnética distribuída em quase todo o espectro eletromagnético muito próximo à distribuição idealizada de radiação de um corpo negro. O gráfico abaixo mostra três curvas espectrais de distribuição de radiação de corpo negro para três hipotéticas estrelas com temperaturas superficiais iguais a 3.000 $\mathrm{K}, 4.000 \mathrm{~K}$ e $5.000 \mathrm{~K}$ respectivamente.

Existem duas leis importantes para a radiação emitida por um corpo aquecido que tenha uma curva de radiação próxima às curvas da Figura 2 , da radiação de corpo negro 12,13 :

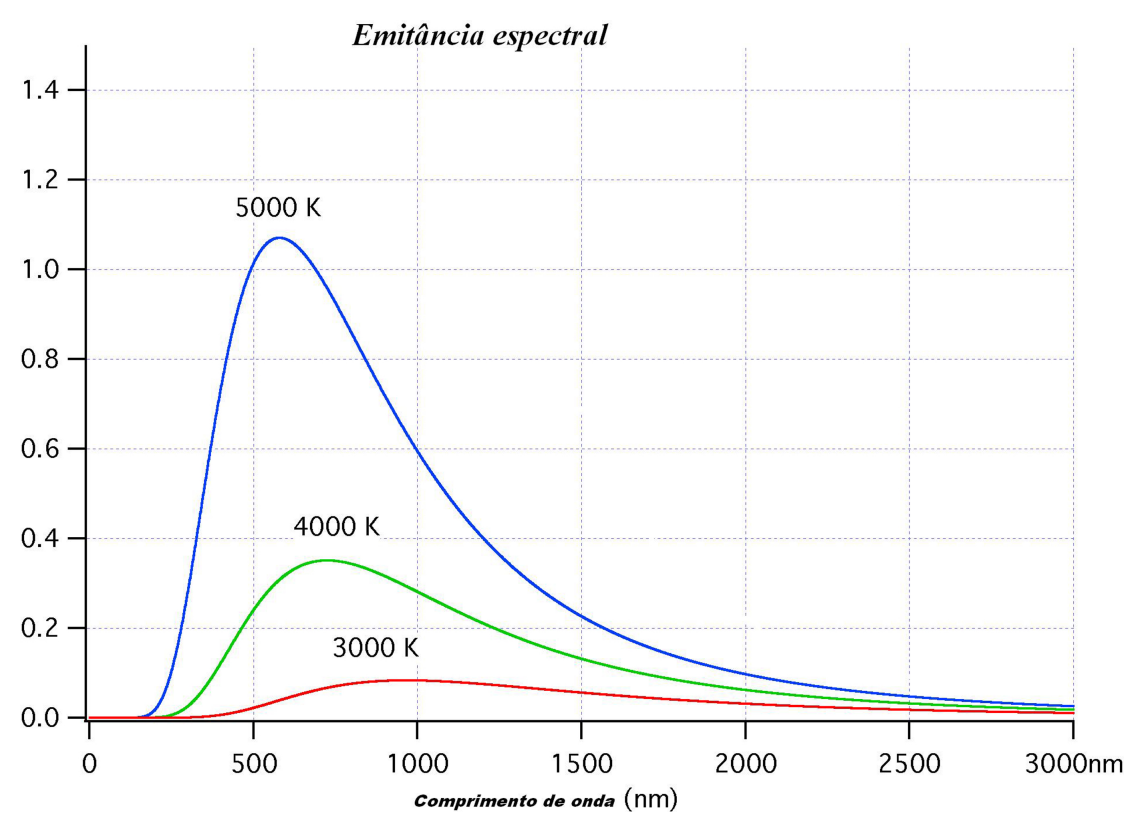

Figura 2: Distribuição espectral de radiação emitida por corpo negro para três diferentes temperaturas. 


\section{- Lei de Stefan-Boltzmann:}

$$
I=\sigma T^{4}
$$

onde $I$ é a intensidade total de toda radiação emitida por uma superfície, $T$ é a temperatura em Kelvin da superfície aquecida e $\sigma=5,67 \times 10^{-8} \mathrm{~W} / \mathrm{m}^{2} \mathrm{~K}^{4}$ é a constante de Stefan-Boltzmann.

Como as estrelas são aproximadamente esféricas a intensidade, potência por unidade de área, é dada por:

$$
I_{0}=\frac{P_{0}}{4 \pi R_{\star}^{2}},
$$

onde $R_{\star}$ é o raio da estrela. Observe que sendo possível medir a intensidade de radiação e a potência na superfície da estrela pode-se consequentemente calcular o tamanho da estrela 15,16. Em Astrofísica a potência ou fluxo de energia de uma estrela e/ou galáxia é denominado de luminosidade. A luminosidade na Astrofísica foi padronizada pela potência do Sol, onde $1 L_{\odot}=3,846 \times 10^{26}$ Watts. A luminosidade ou potência das outras estrelas são medidas como múltiplos ou submúltiplos de $L_{\odot}$.

- Lei do deslocamento de Wien: ao se observar as três curvas de emissão de radiação eletromagnética na figura 2, observa-se que quanto maior a temperatura mais o ponto de máxima emitância da curva se desloca para a esquerda, na direção de menores comprimentos de onda. Essa observação foi formulada por Wien:

$$
\lambda_{\max } T=2,9 \times 10^{-3} \mathrm{~m} \cdot \mathrm{K},
$$

onde $\lambda_{\max }$ é o comprimento de onda onde a intensidade é máxima na curva de radiação de corpo negro, e $T$ é a temperatura em Kelvin da superfície. Uma análise espectral de uma determinada estrela nos possibilita a medir a temperatura superficial de tal estrela e consequentemente calcular com a Lei de StefanBoltzmann a intensidade de radiação $I_{0}$ na superfície da estrela.

Para determinarmos o raio $R_{\star}$ de uma determinada estrela, é necessário medir a intensidade de radiação $I_{1}$ da estrela aqui na Terra com instrumentos de alta sensibilidade. Também é necessário sabermos qual a distância da estrela até a Terra ${ }^{1}$. De forma que a potência de radiação da estrela possa ser calculada com:

$$
P_{0}=4 \pi d^{2} I_{1}
$$

onde $d$ é a distância conhecida da estrela até a Terra. Finalmente, com a posse de $P_{0}$ e usando a Lei de Stefan-Boltzmann podemos calcular o raio da estrela $R_{\star}$ utilizando a equação (4).

Atualmente instrumentos de muita precisão em observatórios espaciais como COROT e Kepler [8 8 medem a intensidade de radiação de uma determinada estrela, então quando um exoplaneta passa em frente à estrela ocorre uma diminuição pequena mas relevante na intensidade medida. Com a revisão das leis de Kepler e da radiação térmica estabelecidas, as quais são fundamentais para a detecção de exoplanetas, o arcabouço teórico para a compreensão da técnica de trânsito está completo. Sendo assim, na próxima seção estudaremos os detalhes do trânsito de planetas.

\section{Técnica do trânsito para detecção de Exoplanetas}

Um exoplaneta ao passar na frente de sua estrela hospedeira causa uma diminuição do brilho da estrela. Essa diminuição pode ser verificada com equipamentos modernos de medição de brilho, bem como também é possível medir o tempo de duração do trânsito. Observe na Figura (3) que o fluxo de energia $P_{0}$ é medido pelos equipamentos antes do ingresso do exoplaneta no trânsito. Quando o exoplaneta está no trânsito ocorre uma queda no fluxo de energia da estrela baixando para um valor $P_{1}$ menor que $P_{0}$. Após o egresso do exoplaneta no trânsito, os equipamentos voltam a medir o fluxo de energia normal da estrela. O intervalo de tempo entre o ingresso e o egresso no trânsito é a duração do trânsito $T_{D}$.

O fluxo de energia ou a potência $P_{0}$ medida antes do ingresso no trânsito pelo exoplaneta é dado pela expressão (4):

$$
P_{0}=I_{0} A_{0}
$$

\footnotetext{
${ }^{1}$ As distâncias das estrelas próximas ao sistema solar passaram a serem conhecidas desde 1838, quando Bessel utilizou o método da paralaxe estelar $14-16$. O observatório espacial Hipparcos da ESA, lançado em 1989 e que operou até 1993, mediu com muita precisão as paralaxes e as distâncias de 118.218 estrelas 17 .
} 


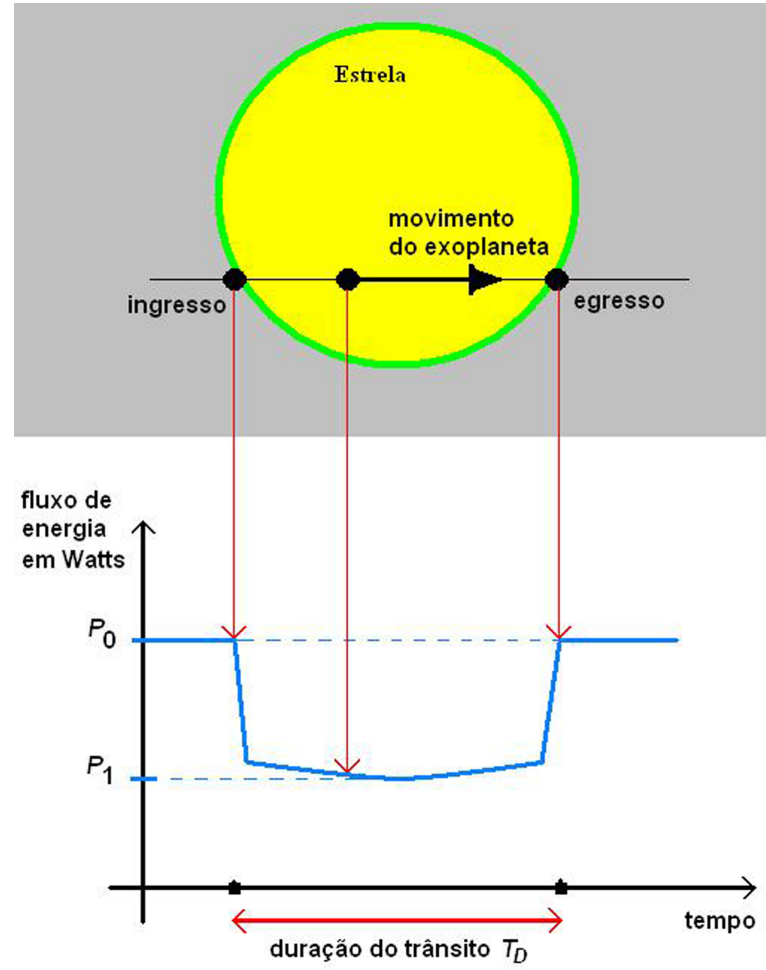

Figura 3: Trânsito de um exoplaneta e o gráfico do fluxo de energia medido durante o trânsito.

onde $A_{0}$ é a área do disco da estrela (devido as longas distâncias a área visível da esfera da estrela é um disco), e $I_{0}$ é a intensidade total da radiação emitida pela estrela.

A potência medida durante o trânsito é dado por:

$$
P_{1}=I_{0} A_{1},
$$

onde

$$
A_{1}=A_{0}-A_{p}
$$

é a área do disco da estrela $A_{0}$ menos a área do disco do exoplaneta $A_{p}$, ou seja $A_{p}$ é a área escurecida pelo exoplaneta. Então, calculando a razão entre o brilho da estrela no trânsito pelo brilho fora do trânsito temos que:

$$
\frac{P_{1}}{P_{0}}=\frac{A_{0}-A_{p}}{A_{0}}=1-\frac{A_{p}}{A_{0}},
$$

$\mathrm{Ou}$

$$
\frac{A_{p}}{A_{0}}=1-\frac{P_{1}}{P_{0}}=\frac{P_{0}-P_{1}}{P_{0}} .
$$

Vamos definir $T_{A}$ como sendo a amplitude da variação do trânsito expressa como uma fração do brilho da estrela fora do trânsito, ou seja,

$$
\frac{P_{0}-P_{1}}{P_{0}}=T_{A} .
$$

Então teremos que a razão entre a área do disco do exoplaneta em relação a área do disco da estrela hospedeira é

$$
T_{A}=\frac{A_{p}}{A_{0}}=\frac{\pi R_{p}^{2}}{\pi R_{\star}^{2}},
$$

onde $R_{p}$ é o raio do exoplaneta e $R_{\star}$ é o raio da estrela hospedeira. Isso resulta numa expressão onde é possível mensurar o tamanho de um exoplaneta através de medidas do trânsito,

$$
R_{p}=T_{A}^{1 / 2} R_{\star} .
$$

Como já foi discutido neste trabalho, um exoplaneta se confirma com convicção quando é possível observar vários trânsitos separados pelo mesmo intervalo de tempo que será o período de uma revolução completa do exoplaneta em torno da estrela hospedeira. Como por exemplo, para o exoplaneta HD 209458 b é possível observar um trânsito a cada 3,5 dias, isso é, o período de revolução é de 3,5 dias; isso porque HD 209458 b está muito próximo de sua estrela hospedeira, a uma distância de 0,046 UA. Só para comparar, Mercúrio o planeta mais próximo do Sol está 0,47 UA e faz uma revolução em torno do Sol a cada 88 dias. Porém para um exoplaneta distante de sua estrela hospedeira, o período para se observar vários trânsitos podem ser demasiadamente longos. Tome por exemplo o planeta Júpiter distante do Sol em 5,2 UA e que gasta quase 12 anos para uma revolução completa. Um exoplaneta em condições semelhantes a Júpiter, seriam necessários 24 anos para se observar três trânsitos consecutivos 2. Se levarmos em conta que somente a partir de 1999 que as observações de exoplanetas através do trânsito tiveram início, com destaques para os trabalhos de dois observatórios espaciais CoRoT [18] e Kepler [8], exoplanetas com tempos de revoluções altos, ainda são tratados como candidatos a planetas extrasolares. Somente a missão Kepler registrou 4.696 candidatos a exoplanetas com longos períodos de revoluções 9

Vejamos como podemos estimar o período de revolução de um exoplaneta com dados de apenas um único trânsito conhecido. Para simplificar vamos assumir que durante o trânsito o exoplaneta cruza

\footnotetext{
${ }^{2} \mathrm{O}$ primeiro trânsito observado inicia a contagem para a primeira revolução do exoplaneta em torno da estrela hospedeira, após 12 anos é possível observar um segundo trânsito. Porém a confirmação se dará com o terceiro trânsito após mais 12 anos.
} 
o centro do disco da estrela visto aqui da Terra. Também assumiremos que a órbita desse exoplaneta é aproximadamente circular e que o raio e a massa da estrela hospedeira pode ser estimado pelo tipo espectral da estrela [15, 16]. Acompanhe pela Figura (4) o trânsito de um exoplaneta a uma distância $a$ da estrela hospedeira quando percorre uma distância $S$, um seguimento de círculo, com uma velocidade orbital $V_{\text {orb }}$.

Visto por um observador aqui da Terra, o diâmetro angular da estrela é o ângulo $\delta$ visto na Figura (4). Temos que o diâmetro da estrela é dado por:

$$
2 R_{\star}=d \delta
$$

ao passo que o percurso $S$ do exoplaneta é dado por

$$
S=(d-a) \delta .
$$

As distâncias entre a Terra e esses sistemas extrasolares observados são da ordem (dezenas para milhares) de anos-luz enquanto que as distâncias dos exoplanetas são da ordem de unidades astronômicas, então temos que $d \gg a$ de forma que a Equação (10) resulta em $S \approx d \delta$, ou seja,

$$
S \approx 2 R_{\star} .
$$

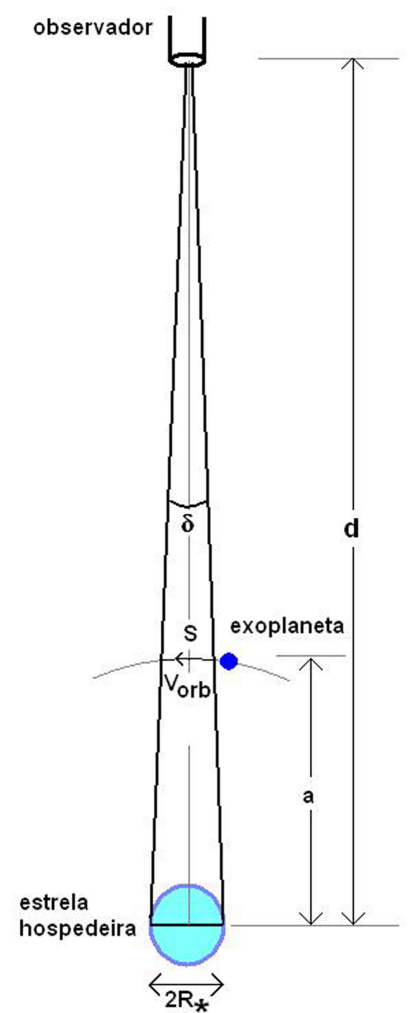

Figura 4: Trânsito de um exoplaneta visto por um observador na Terra
O tempo para percorrer a distância $S$ é o tempo de duração do trânsito $T_{D}$. A velocidade orbital do planeta pode ser dada por:

$$
V_{\text {orb }}=\frac{S}{T_{D}} .
$$

Mas a velocidade orbital do planeta é dada pela expressão da Mecânica Celeste [10,11,16,

$$
V_{\mathrm{orb}}=\left(\frac{G M_{\star}}{a}\right)^{1 / 2},
$$

onde $M_{\star}$ é a massa da estrela. Igualando as duas equações acima teremos que:

$$
\frac{S}{T_{D}}=\left(\frac{G M_{\star}}{a}\right)^{1 / 2} .
$$

Da Mecânica Celeste (1) temos que:

$$
a^{3}=\frac{G M_{\star}}{4 \pi^{2}} \tau^{2} .
$$

Tomemos o cubo da equação 12. Então, substituindo $a^{3}$ conforme dado pela equação $(13)$, obtemos

$$
\frac{S^{3}}{T_{D}^{3}}=\left[\frac{\left(G M_{\star}\right)^{3}}{a^{3}}\right]^{1 / 2}=\left[\frac{\left(G M_{\star}\right)^{3}}{G M_{\star} \tau^{2} / 4 \pi^{2}}\right]^{1 / 2}=\frac{2 \pi G M_{\star}}{\tau} .
$$

Da Equação (11), onde temos $S \approx 2 R_{\star}$, resulta que o período de uma revolução deste exoplaneta será aproximadamente igual a:

$$
\tau=\frac{2 \pi G M_{\star} T_{D}^{3}}{\left(2 R_{\star}\right)^{3}},
$$

ou então,

$$
\tau=\frac{\pi G M_{\star} T_{D}^{3}}{4 R_{\star}^{3}} .
$$

Na próxima seção aplicaremos a técnica apresentada para estudar a deteç̧ão do exoplaneta CoRoT$1 b$.

\section{Estudo do Exoplaneta CoRoT-1b}

O exoplaneta CoRoT-1b foi anunciado em 2007 na constelação do Monoceros. O gráfico do trânsito desse exoplaneta é visto na Figura(5). Observe que o eixo das abscissas não informa o período do trânsito, mas essa informação pode ser obtida nas referências 2,19 21]. A duração do trânsito é de 139 minutos, que se repetem a cada 1,5 dias. 


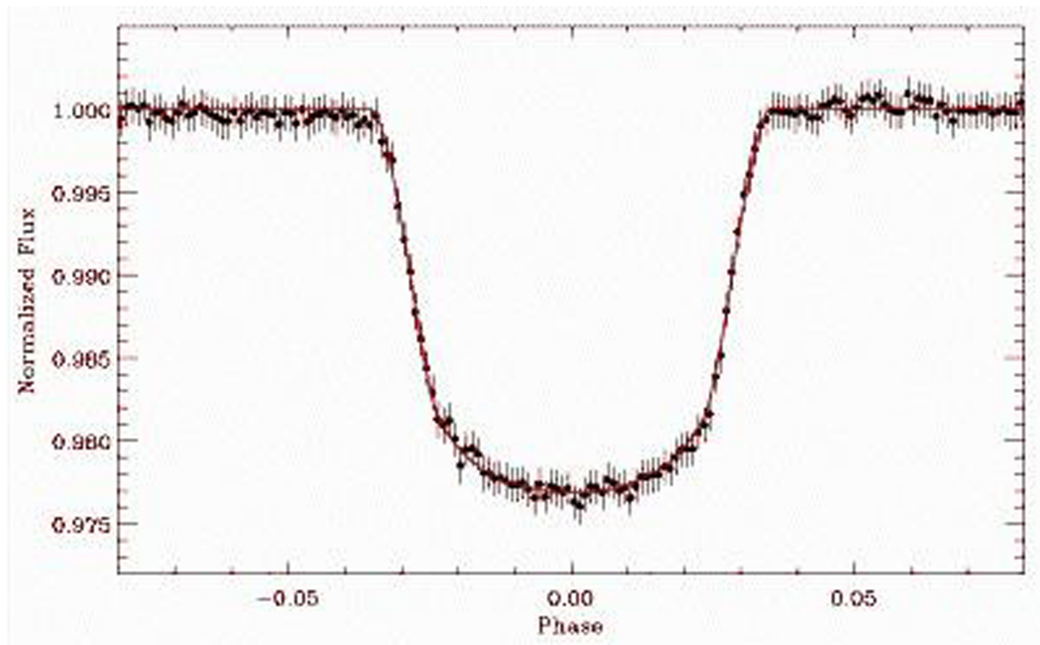

Figura 5: Trânsito do exoplaneta CoRoT-1b. Data: 03 de maio de 2007. Copyright: CoRoT exo-team [19].

Vamos usar os dados do gráfico do trânsito do exoplaneta CoRoT-1b para medir o raio aproximado desse exoplaneta, utilizando a Equação (8),

$$
R_{p}=T_{A}^{1 / 2} R_{\star} .
$$

Como discutido na seção 2 , o raio de uma estrela pode ser determinada através de seus dados espectrais. A estrela hospedeira do exoplaneta CoRoT-1b tem um raio $R_{\star}=1,11 R_{\odot}$ e massa $M=0,95 M_{\odot}$. Observando o gráfico da Figura (5), vemos que o fluxo de energia está normalizado e que $T_{A}$ é aproximadamente:

$$
T_{A} \approx 1,00-0,98=0,02 .
$$

Então o raio $R_{p}$ do exoplaneta CoRoT-1b é então dado por:

$$
R_{p}=0,02^{1 / 2} \times 1,11 R_{\odot}=0,15 R_{\odot} .
$$

Como o raio do Sol é aproximadamente dez vezes maior que o raio do planeta Júpiter, isso resulta que o exoplaneta CoRoT-1b tem raio aproximadamente igual a 1,5 vezes maior que o raio de Júpiter.

Agora podemos utilizar a Equação (14) para calcular o período orbital do exoplaneta CoRoT-1b a partir do tempo de duração do trânsito.

$$
\begin{aligned}
& \tau=\frac{\pi G M_{\star} T_{D}^{3}}{4 R_{\star}^{3}}=\frac{\pi G\left(0,95 M_{\odot}\right) T_{D}^{3}}{4\left(1,11 R_{\odot}\right)^{3}} \\
& =0,695\left(\frac{\mathrm{U} . A .^{3}}{\text { ano }^{2}}\right) \frac{\pi^{3} T_{D}^{3}}{R_{\odot}^{3}}
\end{aligned}
$$

onde usamos o resultado da Equação (2). Então, $T_{D}=139$ minutos ou $T_{D}=2,64 \times 10^{-4}$ anos e o raio do Sol $R_{\odot}=4,64 \times 10^{-3}$ U.A., resulta que o período orbital do exoplaneta CoRoT-1b é:

$$
\tau \approx 1,5 \text { dias. }
$$

O período orbital é muito curto, e isso é facilmente confirmado por observações de repetidos trânsitos intercalados pelo período de apenas 1,5 dias. Esses cálculos dão suporte para prever eventuais períodos de revoluções mais longos de outros exoplanetas e deixam os Astrofísicos de prontidão para repetições dos possíveis trânsitos previstos pela Equação (14), e assim confirmarem se os candidatos a exoplanetas são de fato planetas extra-solares.

Esse curtíssimo período de revolução do exoplaneta CoRoT-1b, de raio 1,5 vezes maior que o raio de Júpiter, implica em uma órbita muito próximo de sua estrela hospedeira. Pode-se confirmar isso pela terceira lei de Kepler (1), a partir da qual podemos medir aproximadamente a distância do exoplaneta CoRoT-1b:

$$
a^{3}=\left(\frac{G M_{\star}}{4 \pi^{2}}\right) \tau^{2},
$$

que resulta em:

$$
a=0,95^{1 / 3} \times\left(4,11 \times 10^{-3}\right)^{2 / 3} \text { U.A. }=0,025 \text { U.A. }
$$

Para fazermos uma comparação de distâncias, observe que o planeta mais próximo do Sol, Mercúrio, está a 0,39 U.A. de distância ao Sol, então o exoplaneta CoRoT-1b está em torno de 15 vezes mais próximo de sua estrela hospedeira do que Mercúrio está do Sol. Esse resultado nos mostra que o exoplaneta CoRoT-1b é um tipo de júpiter-quente orbitando uma estrela com massa e raio similares ao do nosso Sol. 


\section{Considerações Finais}

As recentes descobertas de planetas extra-solares, com destaques aos exoplanetas detectados por meio do método do trânsito, discutido nesse trabalho de ensino de Física, têm chamado a atenção dos estudantes em geral, com destaques aos estudantes de Física. Então a abordagem didática desse trabalho que explica a técnica de detecção de exoplanetas pelo método do trânsito pode ser aplicada para enriquecer os temas físicos envolvidos no método. Observa-se que o conteúdo teórico necessário à compreensão do método de trânsito para a detecção de exoplaneta é relativamente simples embasados nos temas de radiação térmica e leis de Kepler, acessíveis aos estudantes de graduação em Física. Abordamos detalhes simples do método de trânsito explicando todas as passagens matemáticas. No final, apresentamos um exemplo de aplicação prática com o gráfico da curva de radiação do trânsito do exoplaneta CoRot-1b visto na Figura (5).

Na página da internet exoplanets.org (http:// exoplanets . org/table?datasets=explorer) existe uma tabela com dados de muitos exoplanetas e é possível selecionar os exoplanetas que foram descobertos pelo método do trânsito (na opção Example Tables and Save escolha Transit Planets). Na página da internet $[22$ estão disponíveis gráficos de curvas de radiação do trânsito de vários exoplanetas. O professor e/ou estudante pode obter um desses gráficos e utilizá-los para fazer exercícios obtendo o raio do exoplaneta bem como o período e a distância do exoplaneta à estrela hospedeira e ao final comparar as respostas obtidas com os dados fornecidos pela tabela de dados nas referências [21,22].

Temas relacionados à astronomia são naturalmente bem recebidos pelos alunos, despertando o interesse dos discentes por assuntos científicos. Nesse sentido, este trabalho tem o diferencial de conciliar dois temas trabalhados nas disciplinas de física básica de cursos de graduação, radiação térmica e leis de Kepler, a conteúdos relativos à astronomia moderna: deteç̧ão de exoplanetas. Dessa forma, esperamos que este material sirva como uma boa fonte de pesquisa a professores e estudantes que tenham interesse em aprofundar nos temas aqui discutidos.

\section{Referências}

[1] C.A. Haswell, Transiting Exoplanets: Measuring the Properties of Planetary Systems (Cambridge Uni- versity Press, 2010).

[2] C. Kitchin, Exoplanets - Finding, Exploring and Understanding Alien Worlds (Springer, New York, 2012).

[3] S. Seager, Exoplanets (University of Arizona Press, Tucson, 2010).

[4] M. Olivier, Therese Encrenaz, Francoise Roques, Franck Selsis and Fabienne Casoli, Planetary Systems: Detection, Formation and Habitability of Extrasolar Planets (Springer, Berlin, 2008).

[5] R.G.G. Amorim e W.C. Santos, Rev. Bras. Ensino Fís. 39, e1310 (2016).

[6] J.W. Mason (ed), Exoplanets - Detection, Formation, Properties, Habitability (Springer \& Praxis Publishing Ltd, Chichester, 2008).

[7] M. Mayor and P. Frei, New Worlds in the Cosmos The Discovery of Exoplanets (Cambridge University Press, Cambridge, 2003).

[8] https://www.nasa.gov/mission_pages/kepler/ main/index.html.

[9] http://www.nasa.gov/kepler/discoveries

[10] K.R. Symon, Mecânica (Editora Campos, Rio de Janeiro, 1982).

[11] W. Greiner, Classical Mechanics - Point Particles and Relativity (Springer, Berlin, 2002).

[12] H.D. Young and R.A. Freedman, Física IV, Sears Es Zemansky (Pearson, New York, 2009), $12^{\text {a }}$ ed.

[13] S.T. Thornton and A. Rex, Modern Physics for Scientists and Engineers (Cengage Learning, Boston, 2013), 4th ed.

[14] H.M. Nussenzveig, Curso de Física Básica Volume 1 (Editora Blücher, São Paulo, 2004), $4^{\mathrm{a}}$ ed.

[15] A.R. Choudhuri, Astrophysics for Physicists (Cambridge University Press, Cambridge, 2010).

[16] B. Carrol and D. Ostlie An Introduction to Modern Astrophysics (Addison-Wesley Publishing Company, Inc., Boston, 1996).

[17] http://www.esa.int/Our_Activities/Space_ Science/Hipparcos_overview

[18] http://www.esa.int/Our_Activities/Space_ Science/COROT

[19] http://sci.esa.int/corot/40952-transit-ofexoplanet-corot-exo-1b/

[20] http://var2.astro.cz/ETD/.

[21] http://exoplanets.org/

[22] brucegary.net/AXA/x.htm 